\title{
Mother's / Care Giver's Health Seeking Behaviour During Childhood Illness in an Urban Slum of Dhaka city
}

\author{
Mahejabin $\mathrm{F}^{1}$, Parveen $\mathrm{S}^{2}$, Ibrahim $\mathrm{M}^{3}$
}

\begin{abstract}
Objectives: To determine the health seeking behaviour of mothers / care givers of children under 5 years of age during their illnesses. Materials and methods: A descriptive cross-sectional study was conducted among 439 mothers/ care givers of under 5 year old children in an urban slum area of Dhaka city from September 2013 to February 2014. Data were collected through face-to-face interview by using a structured pre-tested questionnaire. The collected data were analyzed using SPSS version 20.0. All analyzed data were presented in the form of percentages. Chi-square test was applied wherever applicable. Results: Out of 439 mothers / care givers, most (90\%) of them sought health care services during their children's illness. [A statistically significant association was found between mother's /care giver's education and sought health care services during illness of children $(p=0.055)$. In the study, $200(50 \%)$ of the respondents consulted drug sellers of medicine shops during their children's illness. Others went to medical college hospital (34.6\%), Government hospitals $(13.5 \%)$, consulted a private practitioners $(11 \%)$ and NGO facilities $(6.3 \%)$. Forty $(9.1 \%)$ respondents did not seek any health care with multiple reasons or responses. Majority $(27,67.5 \%)$ waited for self recovery, $21(52.5 \%)$ had lack of money, $5(12.5 \%)$ did not receive any advice to receive treatment. Four $(10 \%)$ respondents said that the health care facility was too far to receive treatment and $3(7.5 \%)$ respondents did not feel that treatment was necessary. [Health seeking behaviour of the mothers / care givers was statistically highly significant in educated person. They took the child to Govt. hospital $(p=0.001)$ during illness. The relationship between health seeking behaviour and monthly family income of the respondents was statistically significant. The respondents took their child to medical college hospital $(\mathrm{p}=0.040)$ and also consulted drug sellers ( $p=0.038)$ during illness of the child.] Conclusion: Health education and behaviour change communication activities can be undertaken in the slum for mothers / care givers about early recognition of childhood illness and on the importance of seeking early treatment.
\end{abstract}

\section{Key words}

Mothers / caregivers, Health seeking behaviour, Childhood illness, Urban slum.

\section{Introduction}

Children represent the most vulnerable age group in any community; therefore, the child mortality rate is widely used as a demographic measure and an important indicator of the level of welfare in countries. ${ }^{1}$ About 7 million

1. Associate professor (C.C) and Head, Department of Community Medicine, Dhaka Community Medical College, 2. Lecturer, Department of Community Medicine, Dhaka Community Medical College, 3. Consultant, Department of Clinical Biochemistry, Apollo Hospital Dhaka. 
children worldwide under the age of 5 years died in 2011. More than half of these deaths were due to preventable conditions where access to simple and affordable interventions was possible. ${ }^{2}$ However, success in reducing childhood mortality needs more than the availability of adequate health services with well-trained health professionals. As families are the first people responsible for child care, success requires a partnership between health workers and families with community support. ${ }^{3}$ So, improving families' care seeking behaviour could contribute significantly to reducing child mortality in developing countries. ${ }^{4}$

Health-seeking behaviour refers to the sequence of actions that patients and/or their parents take to solve their problem. The sequence of events begins with the identification of symptoms and then the formulation of a treatment strategy by the head of the household in consultation with other adult family members. ${ }^{5}$ Health seeking behaviour is not just a one off isolated event. It is an integral part of a person's, a family's or a community's identity, which had evolved from social, personal, cultural and experiential factors. ${ }^{6}$ A variety of factors have been identified as the leading causes of poor utilization of primary health care services. These include poor socio-economic status, lack of accessibility, cultural beliefs and perceptions, low literacy level of the mothers and large family size. ${ }^{7}$ Reviews of the global literature suggested that factors affecting health seeking behaviour could be classified as cultural beliefs, socio-demographic status, women's autonomy, economic conditions, physical and financial accessibility, disease pattern, and health service issues. ${ }^{7}$ But, in developing countries, cultural practices and beliefs were the most prevalent. ${ }^{8-12}$

In this study, we examined the health-seeking behaviour of mothers / care givers of under 5 years age children in urban slum of Dhaka city because understanding impediments to optimal health-seeking behaviour could greatly contribute to reducing the impact of severe illness on children's growth and development. The results of this study would assist in the reorientation of the ongoing health education programme to improve health seeking behaviour of mothers / care givers.

\section{Materials and Methods}

This descriptive cross-sectional study was done to find out health seeking behaviour of mothers/care givers of below 5 years children during childhood illness from September 2013 to February, 2014 in an urban slum area of Moghbazar in Dhaka city. Samples of 439 mothers/caregivers were interviewed. To be eligible to participate in the study, mothers had to live in households that had children below five years of age. These households were selected by convenient sampling. A structured questionnaire was prepared according to the study objectives. The questionnaire was translated to Bangla and then re-translated back to English to check and minimize any discrepancies. Pre-testing was conducted on $5 \%$ of sample size prior to the actual data 
collection process. Then that pre-tested structured questionnaire was used to collect data on socio-demographic characteristics and health seeking behaviour of mothers / care givers through face-to-face interview in their homes. When there were more than one under-5 children in the household, mothers were asked about the last child. Respondents were not included in the survey if they were not at home at the time of data collection. Data were analyzed using SPSS version 20.0. All analyzed data were presented in the form of percentages. Chi-square test was applied wherever applicable, considering $\mathrm{p}<0.05$ as significant.

\section{Results}

In this study, 439 mothers/care givers were interviewed after fulfilling the inclusion criteria. Most of the study participants, 405 $(92.2 \%)$ were biological mothers of the selected child. Majority 282 (64.7\%) were illiterate or could sign only. One thirty one (29.8\%) respondents were domestic workers, $117(26.6 \%)$ were house wives and $60(13.7 \%)$ were unemployed. Majority 378 (86.1\%) of the respondents belonged to nuclear family and more than half of them $232(52.8 \%)$ had $4-5$ family members. With regard to the socio demographic characteristics of the youngest under five years children, 244 (55.6\%) were female and 195 (44.4\%) were male. 388 $(90.65 \%)$ children were within age group of 49-60 months (Table 1). Mean income and SD was BDT 6902.73; $(\mathrm{SD}= \pm 2476.435)$. About
$60 \%$ of family's monthly income was BDT 4000-8000. (Figure 1). Most 399 (90\%) of the mothers /caregivers sought health care services during child's illness. Only $40 \quad$ (9.1) respondents did not seek health care services (Figure 2). Among those who sought health care, most $200(50 \%)$ of them consulted drug sellers of pharmacy during illness of their children. Among rest, 138 (34.6\%) mothers/ care givers went to medical college hospital, 54 (13.5\%) went to Govt. hospital, 44(11\%) consulted a private practitioner and $25(6.3 \%)$ received NGO facility (Table 3). Among those who did not seek health care service for their children's illness, the reasons for not seeking treatment were diverse. Twenty seven (67.5\%) waited for self recovery, 21 (52.5\%) did not have enough money, 5 (12.5\%) stated that nobody told them to receive treatment. Four $(10 \%)$ respondents said that the health care facility was too far to receive treatment and 3 (7.5\%) respondents did not feel that treatment was necessary (Table 4).

Out of 142 illiterate respondents, $12.7 \%$ did not seek health care compared to $7.4 \%$ in literate group of 297. The difference has borderline significance $(p=0.055)$. There was no significant difference between those seeking and not seeking health care by other differentials like employment status, family type, family size, child's gender or age. (Table: 2). The place from where the respondents sought health care also did not vary by family income, size and child age (Table 5). 


\section{ORIGINAL ARTICLE}

Table 1: Socio-demographic characteristics of mothers/caregivers and selected youngest child (n=439)

\begin{tabular}{|c|c|c|}
\hline Variables & Frequency(n) & Percent (\%) \\
\hline \multicolumn{3}{|l|}{ Primary care giver } \\
\hline Mother & 405 & 92.2 \\
\hline Father & 21 & 4.7 \\
\hline Others & 13 & 3.0 \\
\hline Total & 439 & 100.0 \\
\hline \multicolumn{3}{|l|}{ Education } \\
\hline $\begin{array}{l}\text { Illiterate, or can } \\
\text { sign only }\end{array}$ & 282 & 64.7 \\
\hline Class I to V & 121 & 27.5 \\
\hline $\begin{array}{l}\text { Class VI to Class } \\
\text { VIII }\end{array}$ & 34 & 7.8 \\
\hline Total & 439 & 100 \\
\hline \multicolumn{3}{|l|}{ Occupation } \\
\hline Domestic worker & 131 & 29.8 \\
\hline House wife & 117 & 26.7 \\
\hline Unemployed & 60 & 13.7 \\
\hline Garments worker & 41 & 9.3 \\
\hline Small business & 20 & 4.6 \\
\hline Rickshaw puller & 15 & 3.4 \\
\hline Others & 19 & 4.4 \\
\hline Total & 439 & 100 \\
\hline
\end{tabular}




\begin{tabular}{|lcc|}
\hline Variables & Frequency(n) & Percent (\%) \\
\hline Occupation & 20 & \\
Small business & 15 & 4.6 \\
Rickshaw puller & 19 & 3.4 \\
Others & 439 & 100 \\
Total & & \\
Type of family & 378 & 86.1 \\
Nuclear family & 61 & 13.9 \\
Joint family & 439 & 100 \\
Total & & \\
Family size & 97 & 22.1 \\
$2-3$ & 232 & 52.8 \\
$4-5$ & & \\
\hline
\end{tabular}

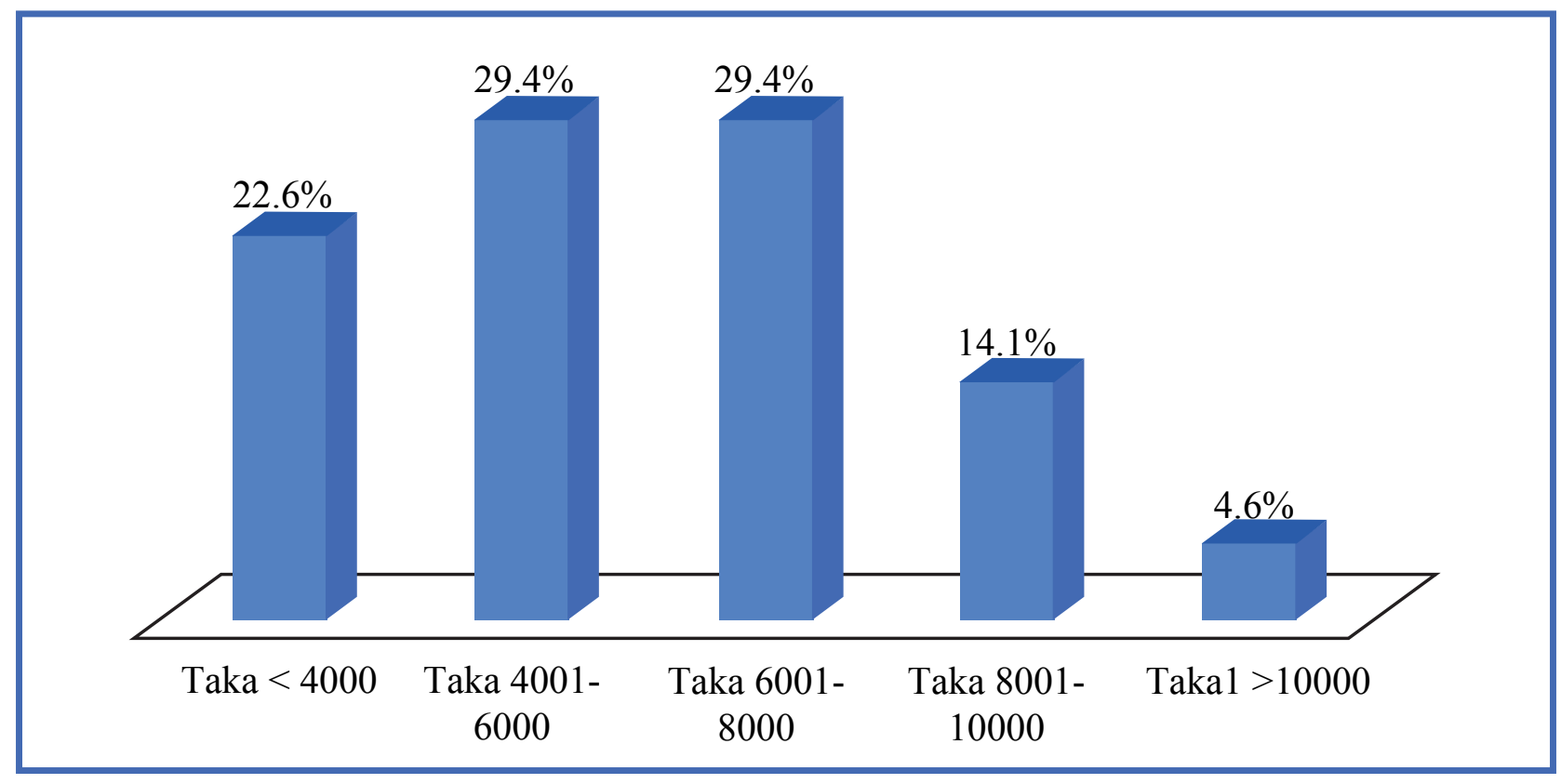

Figure 1: Distribution of the respondents according to monthly family income 


\section{ORIGINAL ARTICLE}

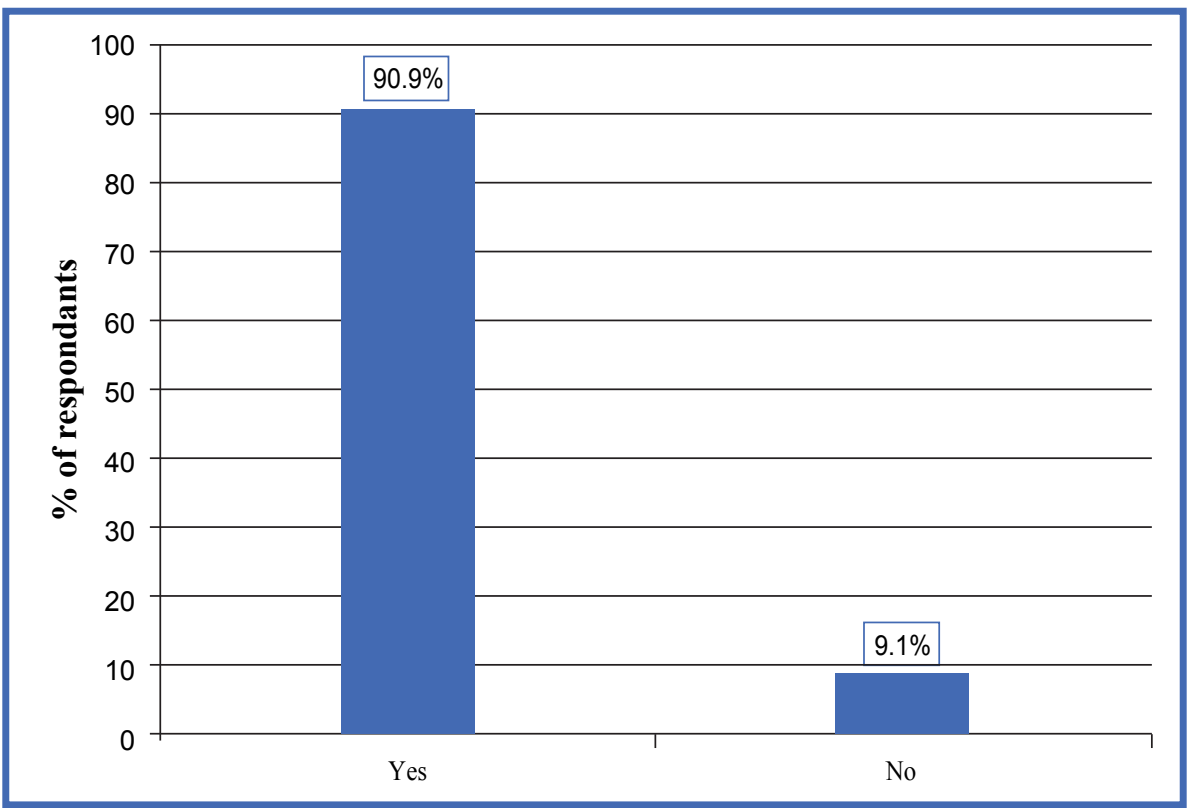

Figure 2: Distribution of the respondents by health care seeking status during illness

Table-2: Relationship between care givers' socioeconomic characteristics and health care seeking behaviour status of the respondents

\begin{tabular}{|c|c|c|c|c|}
\hline Variables & $\begin{array}{l}\text { Sought healt } \\
\text { Yes }\end{array}$ & $\begin{array}{l}\text { care services } \\
\text { No }\end{array}$ & Total & $\begin{array}{c}\text { Chi- } \\
\text { square (P-value) }\end{array}$ \\
\hline \multicolumn{5}{|c|}{$\begin{array}{l}\text { Caregiver's educational } \\
\text { level }\end{array}$} \\
\hline Illiterate & $124(87.32 \%)$ & $18(12.7 \%)$ & $142(100 \%)$ & \multirow{2}{*}{$3.22(0.055)$} \\
\hline Literate & $275(92.59 \%)$ & $22(7.40 \%)$ & $297(100 \%)$ & \\
\hline \multicolumn{5}{|c|}{ Caregiver's occupation } \\
\hline Unemployed & $100(93.33 \%)$ & $6(5.66 \%)$ & $106(100 \%)$ & \multirow[b]{2}{*}{$2.01(0.107)$} \\
\hline Employed & $299(89.78 \%)$ & $34(10.21 \%)$ & $333(100 \%)$ & \\
\hline \multicolumn{5}{|c|}{$\begin{array}{l}\text { Caregiver's type of } \\
\text { family }\end{array}$} \\
\hline Nuclear family & $346(91.53 \%)$ & $32(8.46 \%)$ & $378(100 \%)$ & \multirow[b]{2}{*}{$1.37(0.174)$} \\
\hline Joint family & $52(85.24 \%)$ & $9(14.75 \%)$ & $61((100 \%)$ & \\
\hline \multicolumn{5}{|c|}{$\begin{array}{l}\text { Caregiver's family } \\
\text { member }\end{array}$} \\
\hline $2-3$ & $89(91.75 \%)$ & $8(8.24 \%)$ & $97((100 \%)$ & \multirow{5}{*}{$1.83(0.766)$} \\
\hline $4-5$ & $208(89.65 \%)$ & $24(10.34 \%)$ & $232(100 \%)$ & \\
\hline $6-7$ & $68(94.44 \%)$ & $4(5.55 \%)$ & $72((100 \%)$ & \\
\hline $8-9$ & $20(90.90 \%)$ & $2(9.09 \%)$ & $22((100 \%)$ & \\
\hline$>10$ & $14(87.5 \%)$ & $2(12.5 \%)$ & $16((100 \%)$ & \\
\hline
\end{tabular}




\begin{tabular}{|c|c|c|c|c|}
\hline Variables & $\begin{array}{l}\text { Sought healtl } \\
\text { Yes }\end{array}$ & $\begin{array}{l}\text { care services } \\
\text { No }\end{array}$ & Total & $\begin{array}{l}\text { Chi- } \\
\text { square (P-value) }\end{array}$ \\
\hline \multicolumn{5}{|l|}{ Child sex } \\
\hline Male & $174(89.23 \%)$ & $21(10.76 \%)$ & $195((100 \%)$ & \multirow[t]{2}{*}{$1.164(0.181)$} \\
\hline Female & $225(92.21 \%)$ & $19(7.78 \%)$ & $244((100 \%)$ & \\
\hline \multicolumn{5}{|l|}{ Child age } \\
\hline$<12$ months & $4(100 \%)$ & $0(0 \%)$ & $4(100 \%)$ & \multirow{5}{*}{$1.131(0.889)$} \\
\hline $12-24$ months & $2(100 \%)$ & $0(0 \%)$ & $2(100 \%)$ & \\
\hline 25-36 months & $3(100 \%)$ & $0(0 \%)$ & $3(100 \%)$ & \\
\hline $37-48$ months & $2(100 \%)$ & $0(0 \%)$ & $2(100 \%)$ & \\
\hline $49-60$ months & $388(90.65 \%)$ & $40(9.34 \%)$ & $428(100 \%)$ & \\
\hline
\end{tabular}

Table 3: Distribution of the respondents by order of action during illness $(n=399)$

\begin{tabular}{lcc} 
Order of action during illness & *Frequency(n) & Percent (\%) \\
\hline Consulted a drug seller & 200 & 50 \\
Consulted a homeopath & 23 & 5.8 \\
Consulted an ayurved & 11 & 2.8 \\
Taken to Govt. clinic & 14 & 3.5 \\
Taken to Govt. clinic & 54 & 13.5 \\
Received NGO facility & 25 & 6.3 \\
Consulted a private practitioner & 44 & 11.0 \\
Consulted a traditional healer & 6 & 1.5 \\
Taken to Medical college hospital & 138 & 34.6 \\
\hline
\end{tabular}

*Multiple responses 


\section{ORIGINAL ARTICLE}

Table-4: Distribution of the mother's/ care givers by reasons for not seeking treatment $(\mathrm{n}=\mathbf{4 0})$

\begin{tabular}{llc}
\hline Reasons for not seeking treatment & *Frequency (n) & Percent (\%) \\
\hline Waited for self recovery & 27 & 67.5 \\
Lack of money & 21 & 52.5 \\
Health care facility were unknown & 2 & 5.0 \\
Distance (Far) & 4 & 10.0 \\
Nobody told to go for services & 5 & 12.5 \\
Did not feel that treatment was necessary & 3 & 7.5 \\
& & \\
\hline * Multiple responses & &
\end{tabular}

Table 5: Selected Characteristics of caregivers by type of health seeking place

\begin{tabular}{|l|c|c|c|c|}
\hline $\begin{array}{l}\text { Health care service } \\
\text { provider/institute }\end{array}$ & $\begin{array}{l}\text { Mean } \\
\text { income (BDT) }\end{array}$ & $\begin{array}{l}\text { Mean } \\
\text { education } \\
\text { year of } \\
\text { mothers }\end{array}$ & Size (members) & $\begin{array}{l}\text { Mean Age } \\
\text { of } \\
\text { child (years) }\end{array}$ \\
\hline $\begin{array}{l}\text { Consulted a drug seller } \\
(200)\end{array}$ & 6990.00 & 2.90 & 4.88 & 2.87 \\
$\begin{array}{l}\text { Consulted a } \\
\text { Homoeopath+ Ayurv ed }+ \\
\text { Traditional healer } \\
\text { (23+11+6=40) }\end{array}$ & 7087.50 & 2.98 & 4.53 & 3.05 \\
$\begin{array}{l}\text { Govt Clinic + Govt } \\
\text { Hospital + NGO Facility + } \\
\text { Private Practitioner + } \\
\text { Medical College } \\
(14+54+25+44+138)=275\end{array}$ & 7006.55 & 3.02 & 4.72 & \\
\hline
\end{tabular}




\section{Discussion}

Information on health seeking behaviour is essential to provide need-based health care delivery to any population. The study aimed to determine the mother's /care giver's health seeking behaviour during child illness in urban slum of Dhaka City.

In this study majority of the respondents $(92.2 \%)$ were biological mother of the child which was almost similar with the study done in Bahir dar, Ethiopia. ${ }^{4}$ Two-third of the respondents were illiterate $(65 \%)$ which was consistent with the other studies done in Ethiopia, ${ }^{4}$ and Nigeria. ${ }^{13}$ The current study showed 91\% mothers /caregivers sought health care services during child illness. Almost similar rates of medical care seeking were reported in some countries ${ }^{13-19}$ while others showed lower rates. ${ }^{15,20,21}$ In this study $9.1 \%$ respondents did not seek health care services. Treatments were not sought for $27.3 \%$ sick under-five children in the study done in Ethiopia. ${ }^{4}$ The most frequent action taken by the mothers/ care givers during child illness was consulting drug sellers of pharmacy. Similar findings were observed in the studies done in Yemen ${ }^{1}$ and Kenya. ${ }^{21}$ The least frequent action taken was consulting traditional healers (1.5\%) followed by consulting Ayurved (2.8\%). The study done by Webair et al showed that the least frequent action was consulting traditional healers followed by self treatment ${ }^{1}$ and study done by Mbagaya et al showed that the least frequent action was consulting traditional healers followed by doing nothing. ${ }^{21}$

In the study, the relationship between educational level of the respondents and health care seeking behaviour was found to be borderline statistically significant ( $\mathrm{p}=0.055$ ). In number of studies, the education of the mother is associated with a greater commitment to the care of the child. Educated women tend to provide better health care, hygiene and are more likely to seek help when a child is ill.22 Several studies have reported a positive relationship between maternal education and health seeking behaviour which is consistent with the present study. $15,18,20.21,23,24$ Educated mothers are more likely to be able to read comprehensively and thereby understand better. They are expected to understand health education messages presented in mass media and through other methods more than the less educated ones. The relationship between health seeking behaviour and monthly family income of the respondents was statistically significant. In India, a person's work status and monthly household income were significant explanatory variables for seeking care. ${ }^{25,26}$ Mothers'/ care givers' main reasons for not seeking treatment were waiting for self recovery $(67.5 \%), 52.5 \%$ respondents did not seek treatment for lack of money, and $12.5 \%$ told that nobody told them to receive treatment. Among rest, 10\% respondents told that the reason was distance to receive treatment and $7.5 \%$ respondents did not feel that treatment was necessary. The study done in Ethiopia showed that the main reasons for not seeking care from health facilities were $53.3 \%$ illness not serious, $26.7 \%$ lack of money and $13.3 \%$ did not believe the benefit care seeking from health facilities for such 
childhood illness. ${ }^{4}$ Another study done in Yemen noted that the main reason for not seeking treatment was that the illness was mild/ would resolve. The next common reason was illness was not for medical treatment. ${ }^{1}$ Several studies reported distance from medical care facility, poor facilities, or inability to afford medical care cost as reasons for not receiving treatment. $7,8,21,25,28,29$

\section{Conclusion}

Educational improvement of mothers is recommended. We put emphasis on literacy programs because around $65 \%$ of the respondents had no school education. Messages in the mass media about the importance of schooling are mandatory. Health education programmes should focus on the importance of seeking early treatment for the children and taking drugs as prescribed as well as on raising mother's /care giver's awareness regarding childhood illness.

The study involved a single cross-sectional interview in which mothers/ caregivers recalled their experience of health seeking behaviour during illness of their children. The sample was drawn from an urban slum. It may be small for any general conclusions regarding health seeking behaviour of mothers/ care givers of children below 5 years of age. Larger studies and qualitative researches are necessary for further understanding of health seeking behaviour.

\section{References}

1. Webair HH, Bin-Gouth AS. Factors affecting health seeking behaviour for common childhood illness in Yemen. Patient Preference and adherence.
2013;7:1129-38.

2. Children: reducing mortality [web page on the internet]. Geneva: World health Organization; 2012. Available from:

http://www.who.int/mediacentre/factsheets/fs

178/en/index.html.

3. Child Health in the community- 'Community IMCI': briefing package for facilitators. [Web page on the internet]. Geneva: World Health Organization; 2004. Available from:

http://www.who.int/maternal_child_adolescent/docume nts/9241591/en/index.html.

4. Awoke W. Prevalence of childhood illness and mothers'/caregivers' care seeking behaviour in Bahir Dar, Ethiopia: a descriptive community based cross sectional study. Open journal of Preventive Medicine. 2013;3:155-59.

5. Shaheen R, Rahman MS. Sociology of health care decision: exploration at a public hospital dispensing traditional medicine in Bangladesh. World Health and population. 2001; 4 (available at:

http://www.longwoods.com/product.php? productid $=17593 \&$ cat $=389$ \&page $=1$.)

6. Mackian S. A review of health seeking behaviour: problems and prospects. HSD/WP/05/03. Available at ww.hsd.Isht.ac.uk/publications/hsd_working_papers/05 -03_healthseeking_behaviour.

7. Shaikh BT, Hatcher J. Health seeking behaviour and health service utilization in Pakistan: challenging the policy makers. J Public Health. 2005;27(1):49-54.

8. Katung PY. Socio-economic factors responsible for poor utilization of PHC services in rural community in Nigeria. Niger J Med. 2001;10:28-29.

9. Navaneetham K, Dharmalingam A. Utilization of maternal health care services in Southern India. Soc Sci Med. 2002;55:1849-69.

10. Fatimi Z, Avan I. Demographic, socio-economic and environmental determinants of of utilization of antenatal care in rural setting Sindh, Pakistan. J Pak Med Assoc. 2002;52:138-142.

11. Uchudi JM. Covariates of child mortality in mali:does the health seeking behaviour of the mother matter? J Biosoc Sci. 2001;33:33-54.

12. Stephenson R, Hennink M. Barriers to family planning service use among the urban poor in Pakistan. Asia Pac Popul J. 2004;19:5-26.

13. Uche MC, Benjamin ON, Agwu NA Treatment seeking behaviour of mothers for febrile children in 
some rural parts of Imo State Nigeria: implications for home management of malaria in endemic areas. International Journal of Tropical Medicine. 2009;4(3):132-35.

14. Ndugwa RP, Zulu EM. Child morbidity and care-seeking in Nairobi slum settlements: the role of environmental and socio-economic factors. J Child Health Care. 2008;12 (4):314-28.

15. Abdul Raheem IS, Parakoyi DB. Factors affecting mothers' health care seeking behaviour for childhood illness in a rural Nigerian setting. Early Child Dev Care. 2009;179(5):671-83.

16. Page AL, Hustache S, Luquero FJ. Health care seeking behaviour for diarrhoea in children under 5 in rural Niger: results of a cross-sectional survey. BMC Public Health. 2011;11:389.

17. Motlagh ME, Heidarzadeh A, Hashemian H. Patterns of care seeking during episodes of childhood diarrhoea and its relation to preventive care patterns: national integrated monitoring and evaluation survey ((IMES) of family health. Islamic Republic of Iran. Int J Prev Med. 2012;3(1):60-67.

18. Goa W, Dang S, Yan H. Care seeking pattern for diarrhoea children under 36 months old in rural Western China. PLOS One. 2012;7(8):e43103.

19. Global health observatory: Care seeking for pneumonia: situation and trends [web page on the internet]. Geneva. World Health Organization. Available from; http://www.who.int/ gho/child_health/prevention/pneumonia_text/ en/index. html. Accessed July 12, 2012.

20. Sreeramareddy CT, Shankar RP, Sreekumaran BV. Care seeking behaviour for childhood illness-a questionnaire survey in Western Nepal. BMC Int Health Hum Rights. 2006; 6:7.
21. Mbagaya GM, Odhiamboo MO, Oniang'o RK. Mother's health seeking behaviour during child illness in a rural western Kenya community. Afr Health Sci. 2007; 5(4): 322-27.

22. Gumber A, Berman P. Measurement and pattern of morbidity and utilization of health services. Working Paper no. Ahmedabad; Gujrat Institute of Development Research. 1995; p. 65.

23. Hong TK, Diebley MJ, Tuan T. Factors affecting utilization of health care services by mothers of children ill with diarrhoea in rural Vietnam. Southeast Asian J Trop Med Public Health. 2003;34(1):187-98. 24. Amin R, Shah NM, Becker S. Socioeconomic factors differentiating maternal and child health-seeking behaviour in rural Bangladesh: a cross-sectional analysis. Int J Equity Health. 2010;9:9. 25. Mazzilli C, Davis A. Health care seeking behaviour in Somalia-a literature review. Somalia: UNICEF and European Union; 2009. 52. Available from: www.unicef.org/somalia/SOM_Healthcareseekingbeha viour Report_10-WEB.pdf. Accessed march 2, 2012. 26. Dreze J, Sen AK. India: Economic development and social opportunity. Oxford Cleredon Press; 1995. 27. Engle LP, Menon P, Haddad L. Care and nutrition concepts and measurement. Washington D.C.: International Food Policy Research Institute. 1997. 28. Feikin DR, Nguyen LM, Adazu k. The impact of distance of residence from a peripheral health facility on pediatric health utilisation in rural western Kenya. Trop Med Int Health. 2009;14(1):54-61. 29. Ewing VL, Lalloo DG, Phiri KS. Seasonal and geographic differences in treatment seeking and house hold cost of febrile illness among children in Malawi. Malar J. 2011;10:32. 